Western University

Scholarship@Western

FIMS Publications

Information \& Media Studies (FIMS) Faculty

2016

\title{
A Model of Social Media Engagement: User Profiles, Gratifications, and Experiences
}

Lori McCay-Peet

Dalhousie University, mccay@dal.ca

Anabel Quan-Haase

The University of Western Ontario, aquan@uwo.ca

Follow this and additional works at: https://ir.lib.uwo.ca/fimspub

Part of the Communication Technology and New Media Commons, Library and Information $\underline{\text { Science Commons, Mass Communication Commons, and the Social Media Commons }}$

Citation of this paper:

McCay-Peet, L., \& Quan-Haase, A. (2016). A model of social media engagement: User profiles, gratifications, and experiences . In H. O'Brien \& M. Lalmas (Eds.), Why engagement matters: Cross-disciplinary perspectives and innovations on user engagement with digital media. Heidelberg: Springer Verlag. 


\title{
A Model of Social Media Engagement: User Profiles, Gratifications, and Experiences
}

\author{
Lori McCay-Peet and Anabel Quan-Haase
}

\section{Introduction}

Social media encompass a wide array of platforms ranging from popular sites such as Facebook [19] and Sina Weibo [42] to sites geared to niche communities such as Academia, Pinterest, and Ello. While social media share common features that afford engagement through 'two-way' audience interaction, the diversity in design encountered across sites makes it difficult to identify a set of core functionalities [25]. Generally, social media are defined as 'web sites and applications which enable users to create and share content or to participate in social networking' [57]. The uptake of social media by a wide demographic is undeniable despite recent reports stressing the negative implications of social media adoption and use, including privacy threats [66], large-scale experimentation with users [41], and cyberbullying [60]. Americans spend more time on social media than any other Internet activity [1], with $73 \%$ of online adults using at least one social networking site (SNS) and $42 \%$ using more than one [19]. Social media use has become ubiquitous, and a social media presence is an important aspect of self-presentation, social networking, learning, work, and everyday life for academics [28], healthcare professionals [14], university students [20], and consumers [64].

Cracking the secret of the optimal user interface design to spur social media engagement is a major goal of social media research. A key challenge is that user experience is not based on the interface design and unique features of a social media site alone, but is also driven by characteristics of the social network that is responsible for the provision of content. That is, users join social media platforms where they can interact with their peers and obtain access to content that is amusing, surprising, and relevant to their everyday lives. Sites are expected to continually

\footnotetext{
L. McCay-Peet $(\varangle) \cdot$ A. Quan-Haase

University of Western Ontario, 1151 Richmond St, London, ON, Canada

e-mail: mccay@dal.ca; aquan@uwo.ca
} 
innovate around what engagement means to their user base, by what methods to increase engagement, and how to provide richer and more rewarding experiences.

Adapting O'Brien's [45] definition of user engagement-'a quality of user experience with technology' - we define social media engagement as a quality of user experience with web-based technologies that enable users to interact with, create, and share content with individuals and organizations in their social networks. In this chapter, we focus on user engagement in the context of social media at the level of the individual and network experience-i.e. the experiences that motivate users to engage with content created, shared, or endorsed by people in their social networks and encourage them to linger and return. Understanding social media engagement is valuable on many levels. Educators need to understand how student engagement with social media may extend learning beyond the classroom walls; social media research in the context of education will inform teaching practices and have the potential to affect outcomes. Changes in the interface can interfere with users' ability to voice their opinion, or changes can spur awareness and activism around pressing social or political concerns. Social media companies need to recognize how changes to algorithms and interface design will affect engagement; such knowledge will help keep their users satisfied and guarantee frequent returns.

We identify elements of a model of social media engagement from prior research. By examining both tangible indicators of engagement, such as usage and activity counts, and more abstract indicators relating to positive user experiences, we can begin to understand why people engage at the level they do, with what kinds of social media platforms, and to what effect.

\section{Conceptualizing Social Media Engagement}

Much research has attempted to conceptualize social media engagement. There is, however, a lack of overarching models that bring together various elements of the individual and network experience. Our model of social media engagement in context fills this gap by identifying and integrating six overlapping elements.

1. Presentation of self: The crafting of a personal profile or virtual self over time signifies identity. The combination of various elements and their respective updates yields a virtual self: a user's name, lists of interests, profile picture, content the user chooses to share, and the manner in which users engage with others through social media.

2. Action and participation: Social media sites allow users to perform a variety of tasks such as viewing shared content, posting content, commenting, discussing, and collaborating.

3. Uses and gratifications: Users are motivated to adopt and continue using social media for a variety of reasons, ranging from the information to be exchanged to the social benefits to be derived. 
Social Media Engagement in Context

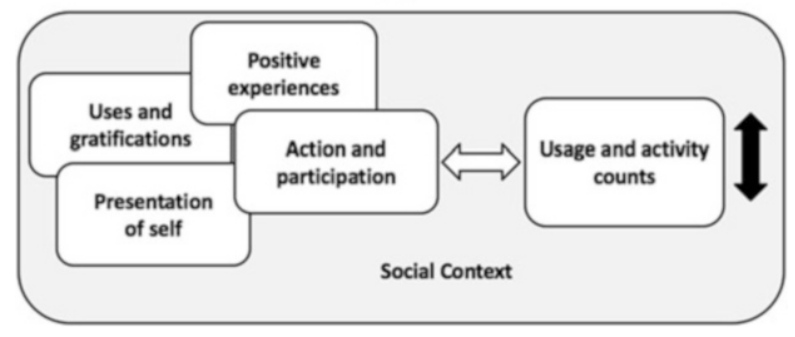

Fig. 1 Model of social media engagement in context

4. Positive experiences: These include the flow, positive emotions, and serendipity, which users may experience during their use of social media.

5. Usage and activity counts: Numerical data relating to users' actions and participation in a site, which can be presented in real time in raw or aggregate form through numeric values or visualizations (e.g. graphs).

6. Social context: Users' social networks within social media sites, including the size and nature of these networks. Social context may be cultural, work, or personal in nature-e.g. a small, close-knit peer group or a large, diffuse network of international social activists.

Figure 1 illustrates our model of social media engagement in context. While each of the six elements is independently useful as a way to both understand and potentially measure engagement, none alone is sufficient. The model proposes that social media engagement may be explained as an iterative and dynamic process that unfolds over time. We use the experience of 'Anna' to exemplify one way in which the model may be used to explain social media engagement.

\footnotetext{
Anna first engages with various social media by crafting and maintaining a personal profile (presentation of self). These social media sites, through features and functions, support and encourage Anna to engage with others in her networks, by enabling her to create content, comment, or simply view other people's profiles and posts (action and participation). Anna's social media interactions are motivated by a number of uses and gratifications (e.g. social and informational) and the positive experiences that underlie her social media usage encourage further engagement, which is reflected in Anna's usage and activity counts. Anna is a frequent social media user who often posts her own content and favourites and interacts with others' action and participation, helping her to both benefit from and make an impact within her social context.
}

Anna's example scratches the surface of the ways in which aspects of social media engagement may be described. The model's elements may be labelled as motivations, behaviours, outcomes, or indicators or measures for evaluation, and some elements may have multiple descriptors. Aspects of positive experience, for example, may include outcomes (e.g. well-being) or motivations (e.g. desire to repeat experience), while aspects of action and participation may serve as indicators of engagement (e.g. number of site visits) or describe behaviours associated with 
social media (e.g. 'listening' [17]). Moreover, the six elements of the model are not discrete. Taking the action and participation element as an example, actions such as following certain individuals or entities, posting comments, or favouriting items all contribute to users' presentation of self as these actions are often visible to their network. As another example, positive experiences may be conceptualized as a motivation for future use and thus overlap with the uses and gratifications element. Our model of social media engagement in context, with all of its complexities, serves as a tool in this chapter for exploring social media engagement.

\subsection{Presentation of Self}

A central part of engagement in social media is the crafting of a profile where aspects of the public self-such as pictures, date of birth, and location-are presented. Sundén [58] has termed the process of providing personal information as 'writing oneself into being', stressing both the creative side of this practice and the fact that it is an active and deliberate process that constitutes an extension of one's offline identity [4, 21]. According to research by Young and Quan-Haase [66], users are actively engaged in decisions about what information to share and with whom, rather than being simply passive consumers of content. Users make decisions about what images to include in their profile, what information to share, and whom to connect with via requests and follows, a process that has been described as data curation of the self [25]. The presentation of self entails a degree of emotional engagement as users confide information about themselves to their imagined audiences [36], an aspect of their social context. The amount of effort that has gone into the presentation of self can be seen as a proxy of the relevance that the person gives to their online identity. A good measure of a user's engagement on a social media site then consists of how elaborate their profile is, in terms of the kind and amount of information they have provided as well as the frequency of profile updates (action and participation). Maintaining an online self requires investment both in time spent updating the profile and creativity with regard to what to include [20].

\subsection{Action and Participation}

Continued engagement on social media can be attributable to the action and participation that social media features afford. For example, Twitter users can create and update their profile (e.g. bio); subscribe to other users' accounts (follow); post text, images, video, and links (tweet); share other peoples' tweets (retweet); reply to tweets (@ reply); include other users in their tweets (@mention); or simply read a stream of real-time tweets of those in their network (timeline). Each of these features allows for different degrees of engagement. That is, a retweet requires less time and 
effort than a reply to a tweet. This differentiation of degrees of engagement has led to some criticisms of measures of engagement with content, as retweets alone cannot show if a user read the content or simply retweeted it without much consideration.

Users of social media sites may vary in terms of the degree to which they participate on these sites. Much research on participation in virtual communities has shown that active contributions come from a small percentage of the community. That is, the large majority only listen in on the conversations without contributing much content. This group has been referred to as 'lurkers' because they are most likely to read posts and messages, but not to post themselves. It is important, however, not to dismiss the relevance of this group to our understanding of engagement. As Crawford [17] argues, 'listeners' 'are actively logging in and tracking the contributions of others; they contribute a mode of receptiveness that encourages others to make public contributions' (p. 527).

When users have a 'voice' [17] by contributing content, they may spark further interest and engagement in other users. Through more participatory activities, such as @mentioning and @ replying, users are not simply putting content out there for others to see, but are also encouraging others in their network to respond, disagree, and share with others. In 2008, when Dave Carroll's guitar was broken on a United Airlines flight, he took to social media, recording and posting a music video on YouTube that went viral with a staggering number of views and tweets, retweets, and @replies on Twitter [23]. The Carroll example not only illustrates the power consumers - celebrities and noncelebrities alike — now wield through social media, but how engagement, through a feedback loop of action and participation, makes it possible for content to go viral, a network-wide indicator of engagement that can create significant spikes in usage and activity counts.

\subsection{Uses and Gratifications}

What motivates social media engagement? Uses and gratifications (U\&G) theory is the most common approach to the study of motivations behind social media use and behaviour [6] and one of the most useful [49, 50]. U\&G is a media and communications theory that explains media selection and continued use through peoples' needs and satisfactions. Smock et al.'s [56] web-based survey of 267 undergraduate students found that three dimensions of use predicted time spent on Facebook: (1) relaxing entertainment, (2) expressive information sharing, and (3) social interaction. Thus, U\&G is useful for explaining motivations behind social media engagement. For the purposes of this chapter, examples of prior U\&G research associated with social media have been selected for discussion (see Table 1). For more background on U\&G, Reinhard and Dervin [52] provide an introduction to its history, theory, and applications, and Quan-Haase and Young discuss its applicability to social media [50]. While there are several motivations for social media adoption, two of the most salient themes throughout the literature are social and informational factors $[32,68]$. 
Table 1 Findings from a selection of U\&G studies of social media

\begin{tabular}{l|l|l}
\hline Research & Social media & Motivations for use \\
\hline $\begin{array}{l}\text { Brandtzaeg \& Heim } \\
\text { (2009) [6] }\end{array}$ & $\begin{array}{l}\text { Various Norwegian } \\
\text { SNSs (e.g. Underskog } \\
\text { and Biip) }\end{array}$ & $\begin{array}{l}\text { Get in contact with new people; keep in } \\
\text { touch with friends; general socializing }\end{array}$ \\
\hline $\begin{array}{l}\text { Coursaris et al. (2013) } \\
\text { [16] }\end{array}$ & Twitter & Information, relaxation, social interaction \\
\hline Joinson (2008) [33] & Facebook & $\begin{array}{l}\text { Social connections, shared identities, } \\
\text { content, social investigation, social } \\
\text { network surfing, status updating }\end{array}$ \\
\hline $\begin{array}{l}\text { Papacharissi \& } \\
\text { Mendelson (2011) }\end{array}$ & $\begin{array}{l}\text { Habitual pastime, relaxing entertainment, } \\
\text { expressive information sharing, escapism, } \\
\text { cool and new trend, companionship, } \\
\text { professional advancement, social } \\
\text { interaction, and meeting new people }\end{array}$ \\
\hline $\begin{array}{l}\text { Quan-Haase \& Young } \\
\text { (2010) [49] }\end{array}$ & $\begin{array}{l}\text { Facebook and instant } \\
\text { messaging }\end{array}$ & $\begin{array}{l}\text { Pastime, affection, fashion, share } \\
\text { problems, sociability, and social } \\
\text { information }\end{array}$ \\
\hline $\begin{array}{l}\text { Whiting \& Williams } \\
\text { (2013) [64] }\end{array}$ & Social media & $\begin{array}{l}\text { Social interaction, information seeking, } \\
\text { pastime, entertainment, relaxation, } \\
\text { communicatory utility, convenience utility, } \\
\text { expression of opinion, information sharing, } \\
\text { and surveillance/knowledge about others }\end{array}$ \\
\hline $\begin{array}{l}\text { Zhang \& Pentina } \\
\text { (2012) [68] }\end{array}$ & $\begin{array}{l}\text { Professional development, emotional } \\
\text { release, information seeking, citizenship } \\
\text { behaviour, social connection, visibility, } \\
\text { self-expression, and interaction with Weibo }\end{array}$ \\
\hline
\end{tabular}

\subsubsection{Social}

Table 1 reflects several perspectives on socially grounded personal, professional, and community or network motivations for social media use. People go to social media to keep in touch with friends [6], for companionship [47], to share problems [49], and for social interaction [16, 47, 64] in general. Sharing everyday life experiences on social media enables feelings of belonging [12] and creates a sense of online community $[33,68]$. An important aspect of social factors that encourage engagement is the social context of social media users; this includes networks of individuals in a common field of work such as those found on sites like LinkedIn, which are sustained by people motivated to interact with others for the purposes of professional development [68] and advancement [47]. Social media also helps users pass time in a fun and entertaining way through social interaction [47, 64, 68], which has the potential to contribute to positive experiences. And finally, some people have broader motivations for social media usage, such as those associated with citizenship 
behaviour [68], which may be spurred by the action and participation of others in the user's networks.

Perhaps one of the most noteworthy findings has been the association between social media usage and social capital return. Social capital is defined as the resources-actual and potential - that a person can obtain from their social networks $[5,15]$. Key gratifications obtained by users of social media are bonding and bridging social capital [48]. Bonding social capital refers to connections with strong ties: those individuals with whom one shares an intimate bond. By contrast, bridging social capital refers to linkages with weak ties: people one associates with, but with whom one is not close. The results of a series of studies revealed that individuals who engage with their Facebook networks show greater levels of both bonding and bridging social capital [20]. What is less clear is whether higher levels of engagement yield higher levels of social capital and thus increase motivations for social media use. A study by Young and Quan-Haase [66] showed an association between the amounts of information a person disclosed on Facebook (presentation of self) and their network size (social context). In this study [66], higher disclosure, as measured by the range of information types disclosed, was associated with larger networks. This indicates that perhaps investments in one's profile (presentation of self) and frequency and range of posts (action and participation) can lead to higher levels of social capital in terms of network size (social context) and increased social motivation for social media use (uses and gratifications).

\subsubsection{Informational}

While the social aspects of social media have garnered a great deal of attention in the literature, social factors are insufficient to fully explain what influences social media engagement [29]. One of the strongest gratification themes in the literature is information seeking and sharing. Prior research has tended to be general in its exploration of the informational motivations of social media use, e.g. sharing 'information' [16] or 'content' [33]. However, other research has been more explicit, specifying qualities or types of information such as 'expressive information sharing' [47] and 'social information' [49] or motivations in the form of behaviour such as 'information seeking' [63]. What is clear is that social media provide an alternative means to traditional media of gathering and relaying a variety of types of information. And while search engines like Google and Yahoo! provide a sophisticated means for seeking specific kinds of information, social media provide a complementary means for sharing and discovering information in a social context ranging from social to political to health topics [40,51]. Often a user's social network has a good understanding of what kinds of news and sources of information may be relevant to a person's current life situation; this kind of targeted information sharing is not available in traditional media.

Social media engagement is in part stimulated by others' presentation of self and action and participation: the provision of interesting tidbits of information, stories, and reports and the inclusion of popular culture that a user may otherwise 
have missed. Social media is about staying 'in the know' about what is trending, what people in one's social network are reading and commenting on, and what is considered 'newsworthy'. Nonetheless, not all social media are considered equally information oriented. Some sites are described as serving more of a social function [44], while others are thought to be more information oriented [26, 32, 35]. Kwak et al. [35] found that $78 \%$ of user pairs on Twitter are one-way rather than reciprocal; that is, a Twitter user may follow a celebrity or a news station, but the user is not likewise followed by the celebrity or news station. Perhaps even more telling, ' $67.6 \%$ of users are not followed by any of their followings in Twitter. We conjecture that for these users Twitter is rather a source of information than a SNS [35]. Below, we briefly examine peoples' use of social media for news gathering and the exchange of everyday life and work information.

\section{News}

Though the credibility of news available through social media is a source of concern [2], it serves to keep people informed of what is happening in their local community and to provide and receive first-hand accounts of events unfolding around the world $[8,31]$. While most Americans prefer to get their news directly from a news organization, they are doing so via multiple sources including social media [2]. More than half of respondents to Pew's social media survey reported they obtained their news from social media sites such as Reddit and Twitter [26]. Thirty percent of Americans reported that they incidentally consume news on Facebook; that is, people visit Facebook for reasons other than to obtain news but encounter news while interacting on the site [44]. Rather than replacing traditional sources such as print, radio, and television, social media provides an additional means for people to consume and engage with news by:

1. Spreading the news and thereby determining what is newsworthy in their social networks

2. Providing their opinion of news items by adding user-generated content

3. Creating their own news, by starting a blog or post on a specific topic of their interest [2]

These three types of engagement have an immediate effect on social media usage and activity counts. It is no wonder then that Twitter encourages users to live-tweet unfolding events, arguing that it increases follower growth and retweets, and it also 'drives engagement on Twitter and builds buzz' [61].

\section{Everyday Life and Work Information}

Social media 'fill a surprisingly useful role in everyday life information seeking' [55] and the larger people's social media networks are, the more information sources people have at their disposal [32]. While social media has been criticized as a 
platform where people can keep their network informed of mundane activities, such as what they ate for breakfast [27], at the other end of the spectrum, people find and share consumer, business, and special event information and learn new things [64]. Social media also enable people to encounter and maintain awareness of professional or work-related information [67]. Through social media, university students share information about social functions, friends, and academic information $[3,18,49]$, making these sites valuable resources. Moreover, people can engage others through social media by asking questions and then getting a timely response [9].

Even though social media sites vary in their reciprocal nature [35], the majority of sites share features that enable a higher level of engagement than seeking, encountering, and maintaining awareness of information in traditional media allows for. Social media sites enable user-specific information dissemination and facilitate discussion of relevant topics that further feed the information available to its user base and create the kind of social context - dynamic and information rich - that has the potential to attract and maintain user interest and a high degree of engagement.

\subsection{Positive Experiences}

Pew reports that $63 \%$ of Facebook users log on to the site at least once a day, with as many as $40 \%$ logging onto the site numerous times throughout the day [19]. Fifty-seven percent of Instagram users visit the site at least once a day (with $35 \%$ doing so multiple times per day), and of those who use Twitter, $46 \%$ are daily visitors (with $29 \%$ visiting multiple times per day) [19]. What makes users of social media sites come back for more-what is driving these usage and activity counts? Important aspects of social media engagement are the positive experiences that compel an individual to return to the site and the attempt to recreate those experiences or seek out new ones. We examine three such positive experiences: flow, emotion, and serendipity.

\subsubsection{Flow}

A key concept of user engagement is Csikszentmihalyi's notion of flow, an experiential psychological state of total or deep involvement 'that is so desirable that they wish to repeat it as often as possible' [29]. It is, therefore, no wonder that social media use is often likened to addiction in the popular press [54] and usage and activity counts are popular as a quick and dirty measure of user engagement in the context of social media. Survey research on undergraduate students who identified themselves as heavy Facebook users found that the site was used to communicate and maintain friendships; the playfulness, subject involvement, and focused attention students perceived they experienced through Facebook use helped to explain students' deep involvement in the SNS [11]. 


\subsubsection{Emotion}

People react to external stimuli through positive emotions such as comfort and pleasure or negative emotions such as social rejection and disgust, which may prompt approach or avoidance behaviours [30]. Social media engagement has been shown to be linked to the emotionality of the content presented on these sites, including (1) the emotions associated with the presentation of self, and (2) the emotions that result from various levels of action and participation [34]. In terms of the crafting of the self, social media engagement can be an emotional experience: the content presented is a reflection of our identity. What we present and how others engage with this content via likes, retweets, and favourites influence our sense of involvement, 'a cognitive and emotional response to media' [46]. Second, the emotions expressed through social media content, such as posts or comments, are central to engagement. Findings from case studies on social media-based public forums indicate that angry discussions were more influential (e.g. garner more replies) than those characterized by anxiety [13]. In the second case study at the end of this chapter, we examine research that shows how both negative and positive emotions in response to social media content influence users' level of social media engagement [34].

\subsubsection{Serendipity}

Serendipity is 'an unexpected experience prompted by an individual's valuable interaction with ideas, information, objects, or phenomena' [39]. Serendipity is a positive experience relating to the use of social media, resulting from a dynamic, messy information space that is unpredictable and full of surprises. McCay-Peet et al. [38] found that social media environments may be better at leading to the unexpected, a facet of serendipity, than websites, databases, and search engines. Serendipitous experiences are often social in nature, involving a transfer of knowledge or information between people [37], a function for which social media platforms are aptly designed (see uses and gratifications). While the 'noise' within social media and its potential to distract can be a source of negative experiences, social media also afford positive user experiences: discovering unexpected and useful resources, meeting new people, finding consumer products, becoming informed of news, and helping people make connections between ideas.

Distrust of mainstream media due to its perceived potential to distort and provide imbalanced coverage has led some people to turn to social media. Through research on news-reading behaviour, for example, Yadamsuren and Heinström [65] found that some people use social media such as Boing Boing, a collaborative blogging site, to get their news incidentally or serendipitously from sources they perceive are more transparent. Research also indicates that postgraduate students come across information related to their academic work serendipitously on social media, which encourages further engagement with social media. The students recognize that 
time spent engaging on social media (action and participation) is an investment in serendipity both from the perspective of the person sharing content and those exposed to it. And while each parcel of time allotted to social media may not pay off in the form of serendipitous discoveries, for those times it does, it is worth the effort [18] (uses and gratifications).

\subsection{Usage and Activity Counts}

From a broad, economic perspective, the level of activity or the number of monthly active users (MAUs) on social media is the industry's primary measure of user engagement and an indicator of a social media site's financial health [10]. Researchers have also equated repeat visits to social media with user engagement. Pew, for instance, reported, 'Facebook and Instagram exhibit especially high levels of user engagement: a majority of users on these sites check in to them on a daily basis' [19]. However, we refer to usage and activity counts here also as those numbers that are presented to individual users in raw and aggregate form that serve to create a feedback loop of engagement.

There is an abundance of numbers on social media, exemplified through the social network Academia, a platform for academics to share their research. The site allows scholars to easily monitor the number of people who, for example, (1) follow their work, (2) view or download their papers, and (3) view their profiles. Various data relating to users' interactions with Academia content are collected, summarized, and visualized for each profile. A map of the world, for example, indicates the country of origin of those who viewed an Academia profile in the past 30 days. These numbers, raw, aggregate, and visualized, may not only serve to give users a sense of self-worth as Michael Harris [43] suggests, but may also influence, for example, whether academics continue to upload papers and follow other academics' work. As previously mentioned (Sect.2.2), the summaries of users' action and participation have the potential to influence further action and participation. Moreover, usage and activity counts also provide a type of summary of the social media user for others to view-e.g. how many people downloaded or liked the content they shared-which may or may not mirror the identity the user is attempting to reflect (presentation of self).

\subsection{Social Context}

User engagement is shaped by the social context in which interactions take place in social media. Different contexts necessitate the use of diverse indicators, measures, and indices of engagement because norms, values, and customs will vary. Also the role played by the content shared varies greatly across contexts, reflecting the many uses and gratifications of social media. Though there are few barriers within 
social media to share content, some social media are more associated with one type of information than another (e.g. leisure versus work) due to their technological affordances (e.g. image and text oriented) and because some social media attempt to attract a specific demographic (e.g. professionals, academics). Moreover, within social media sites, who people imagine their audience to be affects what information they share [36] (presentation of self). While some people choose to mix the personal with the professional through a single social media site, others choose to create separate profiles to reflect the context of their social media contributions, for example, scientists who keep a separate personal and professional Facebook account [62]. Distinctions made by users between their various social media accounts, and accounts bound within disparate social contexts, may suggest differences in the type, quality, and level of engagement in each. We examine the social context of digital humanities scholars' user engagement in the first case study to follow.

\section{Conclusions}

In this chapter, we propose a model of social media engagement which comprises six related elements: (1) presentation of self; (2) action and participation; (3) uses and gratifications; (4) positive experiences; (5) usage and activity counts; and (6) social context. Together, the elements paint a picture of the degree and quality of social media engagement that helps explain why people choose to adopt social media and continue to engage with it. We mainly focus on the positive side of user engagement by discussing how social media can promote feelings of belonging to a community and enable people to keep up with the news. However, there is also a growing body of literature on the negative aspects of social media engagement which raise a number of important questions.

1. Manipulation of content. For those planning a trip, wishing to buy a product online, or pondering the legitimacy of a company, there is often a wealth of user reviews or indicators (e.g. 'likes'), which help consumers make informed decisions; but buyer beware. Some companies exist to create false reviews and inflate reputations [24]. How can false user engagement be vetted?

2. Unpaid workforce. Social media users are creating content and the 'buzz' which helps drive social media engagement [61], increasing the bottom line of social media companies [7]. Is this fair? Can and should engagement be monetarily compensated?

3. Engagement extremes. Is it possible to be too engaged with social media, so much so that people are crashing their cars while using social media [22]? Is engagement something that should always be increased, encouraged?

4. Numbers obsession. Many of the social interactions we have online have been reduced to sheer numbers [43], e.g. votes on Reddit submissions, follower counts on Twitter, and blog post views. How is the numbers focus impacting users' selfworth? Should it be mediated? 
While engagement is framed by the social media industry as a numbers game with higher being 'better', the questions above suggest a need to look beyond usage and activity counts to understand how to build sustainable social media engagement.

Exploring abstract experiences such as flow, emotionality, and serendipity from both positive and negative perspectives may be particularly fruitful for unlocking why people engage at the level they do with different types of social media and to what effect. Future research on user engagement with social media may examine, for example, whether some people avoid social media due to the same experiences that draw others to it (e.g. flow, serendipity). Moreover, what interface features support social media engagement and what features may also help curb engagement when disengagement is preferable? Understanding these more complex elements of engagement will help inform the design of social media to the benefit of users.

\section{Case Studies of Social Media Engagement}

We discuss two case studies to illustrate the usefulness of the model of social media engagement to the study of user engagement in different kinds of social contexts. Case Study 1 explores how digital humanities scholars engage with their community (social context) on Twitter through modes of action and participation, scholars' motivations for engagement (uses and gratifications), and the positive experiences derived from engagement. Case Study 2 examines how the networked transmission of emotion (an aspect of positive experience) on Facebook through the presentation of self (e.g. pictures, updates) influences action and participation (e.g. posting comments, likes).

\section{Case Study 1: Digital Humanities Scholars' Use of Twitter}

This case study examines user engagement in the social context of scholarly digital communication among digital humanities scholars. Specifically, it draws from data collected as part of a multi-year project, 'Digging DH', which examines the role of electronic resources and social media in the scholarly practices of digital humanists (see DiggingDH.com). The focus on digital humanities scholars is pertinent, as these scholars have been described as early adopters of social media and have also reflected on what their engagement on these sites means for their scholarly practice [59]. What motivates these scholars to participate and engage with content on Twitter? As part of the larger Digging DH project, 15 semi-structured interviews were collected in 2013 at the Digital Humanities Conference with graduate students, faculty, scholars, and practitioners [51]. We identified engagement in the context of scholarly communication among digital humanities scholars that map onto three of the elements of social media engagement outlined in this chapter. 


\section{Uses and Gratifications (Informational and Social)}

The content of a tweet yielded the greatest level of engagement; often timely discussions, controversial topics, or personal disputes led to the involvement of large segments of the community. For digital humanities scholars, social media engagement was primarily motivated by finding and sharing information and disseminating research as well as the building of new connections with fellow digital humanities scholars who shared their interests.

\section{Action and Participation}

The amount of time spent on Twitter varied considerably among scholars. Some were heavy users of Twitter and owned multiple accounts, while others were only sporadic users, visiting Twitter primarily during conferences as a form of backchanneling (see also [53]). For example, some described viewing their Twitter feeds when there was a conference they were unable to attend, providing a means to follow conference discussions from afar. There were also variations in how people engaged with content on Twitter. Not all users were equally active participants; some indicated they felt most comfortable as 'listeners' [17] or 'lurkers.'

\section{Positive Experiences}

Twitter represented a creative filler of downtime; one reported, 'I tend to use Twitter in interstitial moments in my day. So if I am catching public transport or if I am sitting in front of a TV and not entirely engrossed in my program'. This finding fits well with the U\&G literature, which reports that one of users' primary gratifications is pastime (e.g. [47, 49, 64]). Scholars also noted the importance of Twitter as a means to discover unexpected information sources (serendipity), which is in accord with the U\&G finding of informational motivations (e.g. [16, 33]). Scholars stumble upon content on Twitter, keeping them informed of research in their field without searching for it. When Melissa Terras, a digital humanities scholar, tweeted and blogged about her research papers (presentation of self; action and participation), she observed a drastic increase in the number of monthly downloads of these papers [59], suggesting others in her field were able to encounter her research via social media. Terras' experience also underlines the importance of listeners to social media engagement; the visible increase in downloads encouraged Terras to continue blogging about her research and encourage other researchers to do the same, even though not all listeners necessarily retweeted her posts or commented on them (action and participation).

However, just as positive experiences have the potential to increase social engagement, negative experiences have the potential to decrease it. Engagement on Twitter had a negative connotation for some scholars because it distracted them 
from their work. Scholars also described feeling overwhelmed by the amount of content and the difficulty of engaging deeply with short snippets of information.

In summary, in the context of scholarly communication among digital humanities scholars, social media engagement on Twitter demonstrates large variability in terms of uses and gratifications, action and participation, and positive experiences. Findings from the Digging DH project provide insights into how social media engagement may impact scholarly process and output.

\section{Case Study 2: The Facebook Experiment}

Our second case study is based on a research paper, which examines emotional contagion - the transfer of emotional states—on Facebook [34]. Findings inform our understanding of the relationship between positive experiences, emotion in particular, and other elements of the model of social media engagement including presentation of self and action and participation.

Experiments were conducted by computational social scientists on the popular social media site Facebook to debunk the widely believed assumption that when you are immersed in an environment in which people share positive posts, updates, and images depicting others having fun, this leads to feelings of social inadequacy and even depression. In other words, the expression of positive emotion on social media can trigger negative emotion in others.

Two experiments ran for 1 week in 2012 and manipulated the amount of positive and negative content that randomly selected users $(N=689,003)$ would see in their news feeds. Each experiment had a control and experimental condition with a sample size of approximately 155,000 per condition. For the two experimental conditions, the researchers made changes to Facebook's ranking algorithm, filtering content to reduce the amount of negative or positive content visible in users' news feeds, though all content was still accessible by viewing friends' content directly (e.g. via friends' walls).

Though the study has been criticized for ethical problems relating to privacy and informed consent [41, 63], the results provide some insights for our understanding of social media engagement. Specifically, it illustrates that engagement can occur at a deep level without much awareness on the part of users and demonstrates the relationship between positive experiences and different elements of the model of social media engagement, namely, presentation of self and action and participation.

\section{Presentation of Self}

In contrast to popular belief, the Facebook experiment found that exposure to emotions led users to express the same emotions (i.e. emotional contagion) through their posts and comments (presentation of self). For example, those users in the 
reduced negative emotion condition wrote posts in the days that followed with a lower percentage of negative words and a higher percentage of positive words.

\section{Action and Participation}

The research also found that the omission of emotional content, whether negative or positive in nature, led to what the researchers referred to as a withdrawal effect:

People who were exposed to fewer emotional posts (of either valence) in their news feeds were less expressive overall on the following days, addressing the question about how emotional expression affects social engagement online [34].

In other words, emotion appears to share a relationship with level of action and participation: lower levels of emotion lead to lower levels of action and participation.

Findings from the Facebook experiment have implications for designers of social media and their users. The experiments show that the emotional valence of content-positive or negative-has the potential to influence action and participation and thus usage and activity counts. The findings underline the potential of sentiment analysis to understand spikes in uses and activity counts. The success of the experiment also raises ethical concerns. The research suggests that changes to algorithms that effectively manipulate emotion are possible: increasing the amount of emotional content seen in users' news feeds can raise usage and activity counts. Should this power to manipulate go unchecked? As we asked in the chapter conclusion above, is social media engagement something that should always be increased, encouraged?

Acknowledgements This paper was funded by SSHRC Insight Grant No. R3603A13 given to A. Quan-Haase, a Western ADF internal grant, and by GRAND NCE, subproject NEWS2 \& DIGHUM.

\section{References}

1. Adler, E.: Facebook is crushing all other social networks in the time each user actually spends on the site. Business Insider. http://www.businessinsider.com/ (2014). Cited 14 Jan 2015

2. American Press Institute: The media insight project: the personal news cycle. http://www. americanpressinstitute.org/ (2014). Cited 14 Jan 2015

3. Bonds-Raacke, J., Raacke, J.: MySpace and Facebook: identifying dimensions of uses and gratifications for friend networking sites. Individ. Differ. Res. 8(1), 27-33 (2010)

4. Bortree, D.S.: Presentation of self on the Web: an ethnographic study of teenage girls' weblogs. Educ. Commun. Inf. 5(1), 25-39 (2005)

5. Bourdieu, P., Wacquant, L.: An Invitation to Reflexive Sociology. University of Chicago Press, Chicago (1992)

6. Brandtzg, P.B., Heim, J.: Why people use social networking sites. In: Ozok, A.A., Zaphiris, P. (eds.) Lecture Notes in Computer Science, vol. 5621, pp. 143-152. Springer, New York (2009) 
7. Brown, B.A., Quan-haase, A.: "A workers' inquiry 2.0": an ethnographic method for the study of produsage in social media contexts. tripleC 10(2), 488-508 (2012)

8. Cao, Q., Lu, Y., Dong, D., Tang, Z., Yongqiang, L.: The roles of bridging and bonding in social media communities. J. Am. Soc. Inf. Sci. Technol. 64(8), 1671-1681 (2013)

9. Carmichael, G. (gailcarmichael): Anyone at Carleton_U know the name of the main department in charge of student records? I forget!. Twitter. https://twitter.com/gailcarmichael/status/ 502116574850187264 (2014). Cited 15 Jan 2015

10. Chan, E.: Twitter assuages growth concerns for now as shares soar 35 pct. Yahoo! Finance. http://finance.yahoo.com/ (2014). Cited 14 Jan 2015

11. Chan, W.W.L., Ma, W.W.K.: The influence of playfulness and subject involvement on focused attention when using social media. J. Commun. Educ. 1(1), 16-27 (2014)

12. Chen, G.M.: Tweet this: a uses and gratifications perspective on how active Twitter use gratifies a need to connect with others. Comput. Hum. Behav. 27(2), 755-762 (2011)

13. Choi, S.: Flow, diversity, form, and influence of political talk in social-media-based public forums. Hum. Commun. Res. 40, 209-237 (2014). doi:10.1111/hcre.12023

14. Chretien, K.C., Kind, T.: Social media and clinical care: ethical, professional, and social implications. Circulation 127(13), 1413-1421 (2013)

15. Coleman, J.S.: Social capital in the creation of human capital. Am. J. Sociol. 94(Suppl.), S95S120 (1988)

16. Coursaris, C.K., Sung, J., Van Osch, W., Yun, Y.: Disentangling Twitter's adoption and use (dis)continuance: a theoretical and empirical amalgamation of uses and gratifications and diffusion of innovations. Trans. Hum.-Comput. Interact. 5(1), 57-83 (2013)

17. Crawford, K.: Following you: disciplines of listening in social media. Continuum 23(4), 525535 (2009). doi:10.1080/10304310903003270

18. Dantonio, L., Makri, S., Blandford, A.: Coming across academic social media content serendipitously. Proc. Am. Soc. Inf. Sci. Technol. 49(1), 1-10 (2012)

19. Duggan, M., Smith, A.: Social media update 2013: $42 \%$ of online adults use multiple social networking sites, but Facebook remains the platform of choice. Pew Research Internet Project. http://www.pewinternet.org/ (2014). Cited 14 Jan 2015

20. Ellison, N.B., Steinfield, C., Lampe, C. The benefits of Facebook "friends:" Social capital and college students' use of online social network sites. J. Comput.-Mediat. Commun. 12, 1143 1168 (2007)

21. Gibbs, J.L., Ellison, N.B., Heino, R.D.: Self-presentation in online personals the role of anticipated future interaction, self-disclosure, and perceived success in Internet dating. Commun. Res. 33(2), 152-177 (2006)

22. Gorman, R.: Woman, 32, dies in head on crash seconds after Facebook post from behind wheel about how she loved Pharrell hit Happy. Daily Mail. http://www.dailymail.co.uk/ (2014). Cited 14 Jan 2015

23. Greenfield, D.: Response to Dave Carroll YouTube video: 9 tweets. Social Media Today. http:// www.socialmediatoday.com/ (2014). Cited 14 Jan 2015

24. Griffith-Greene, M.: Fake online reviews: 4 ways companies can deceive you. CBC News. http://www.cbc.ca/ (2014). Cited 14 Jan 2015

25. Hogan, B., Quan-Haase, A.: Persistence and change in social media. Bull. Sci. Technol. Soc. 30(5), 309-315 (2010)

26. Holcomb, J., Gottfried, J., Mitchell, A.: News use across social media platforms. PewResearch. http://www.journalism.org (2013). Cited 8 Sep 2014

27. Hough, M.G.: Keeping it to ourselves: technology, privacy, and the loss of reserve. Technol. Soc. 31, 406-413 (2009)

28. Housewright, R., Schonfeld, R.C., Wulson, K. Ithaka S + R I Jisc I RLUK UK Survey of Academics 2012, pp. 1-92 (2013)

29. Huang, L.-Y., Hsieh, Y.-J., Wu, Y.-C.J.: Gratifications and social network service usage: the mediating role of online experience. Inf. Manag. 51(6), 774-782 (2014)

30. Jarymowicz, M.: Understanding human emotions. J. Russ. East Eur. Psychol. 50(3), 9-25 (2012). doi:10.2753/RPO1061-0405500301 
31. Java, A., Song, X., Finin, T., Tseng, B.: Why we twitter: understanding microblogging. In: Proceedings of the 9th WebKDD and 1st SNA-KDD 2007 Workshop on Web Mining and Social Network Analysis, pp. 56-65. ACM, New York (2007)

32. Johnson, P.R., Yang, S.-U.: Uses and gratifications of Twitter: an examination of user motivation and satisfaction. In: Proceedings of Annual Association for Education in Journalism and Mass Communication Conference. http://citation.allacademic.com//meta/p_mla_apa_ research_citation/3/7/6/3/6/pages376367/p376367-1.php (2009). Cited 14 Jan 2015

33. Joinson, A.N.: 'Looking at', 'looking up' or 'keeping up with' people? Motives and uses of Facebook. In: Proceedings of the Twenty-Sixth Annual SIGCHI Conference on Human Factors in Computing Systems, pp. 1027-1036. Association for Computing Machinery Press, New York (2008)

34. Kramer, A.D.I., Guillory, J.E., Hancock, J.T.: Experimental evidence of massive scale emotional contagion through social networks. Proc. Natl. Acad. Sci. USA 111(24), 8788-8790 (2014)

35. Kwak, H., Lee, C., Park, H., Moon, S.: What is Twitter, a social network or a news media? In: Proceedings of the 19th International Conference on World Wide Web - WWW '10. p. 591. ACM, New York (2010)

36. Marwick, A.E., Boyd, D.: I tweet honestly, I tweet passionately: twitter users, context collapse, and the imagined audience. New Media Soc. 13(1), 114-133 (2010)

37. McBirnie, A., Urquhart, C.: Motifs: dominant interaction patterns in event structures of serendipity. Inf. Res. 16(3), Paper 494 (2011)

38. McCay-Peet, L., Toms, E.G., Kelloway, E.K.: Examination of relationships among serendipity, the environment, and individual differences. Inf. Process. Manag. 51, 391-412 (2015)

39. McCay-Peet, L., Toms, E.G.: Investigating serendipity: how it unfolds and what may influence it. J. Assoc. Inf. Sci. Technol. 66(7), 1463-1476 (2015)

40. McDonnell, M., Shiri, A.: Social search: a taxonomy of, and a user-centred approach to, social web search. Program-Electron Lib. 45(1), 6-28 (2011)

41. McNeal, G.: Facebook manipulated user news feeds to create emotional responses. Forbes Magazine. http://www.forbes.com/ (2014). Cited 14 Jan 2015

42. Millward, S.: Check out the numbers on China's top 10 social media sites. TechInAsia. http:// www.techinasia.com (2013). Cited 14 Jan 2015

43. Mirani, L.: What it feels like to be the last generation to remember life before the internet. Quartz. http://qz.com/ (2014). Cited 14 Jan 2015

44. Mitchell, A., Kiley, J., Gottfried, J., Guskin, E.: The role of news on Facebook: common yet incidental. http://www.journalism.org/2013/10/24/the-role-of-news-on-facebook/ (2013). Cited 14 Jan 2015

45. O'Brien, H.: Exploring user engagement in online news interactions. Proc. Am. Soc. Inf. Sci. Technol. 48(1), 1-10 (2011). doi:10.1002/meet.2011.14504801088

46. Oeldorf-Hirsch, A., Sundar, S.S.: Posting, commenting, and tagging: effects of sharing news stories on Facebook. Comput. Hum. Behav. 44, 240-249 (2015). doi:10.1016/j.chb.2014.11.024

47. Papacharissi, Z., Mendelson, A.: Toward a new(er) sociability: uses, gratifications and social capital on Facebook. In: Papathanassopoulos, S. (ed.) Media Perspectives for the 21st Century, pp. 212-230. Routledge, New York (2011)

48. Putnam, R.D.: Bowling Alone. Simon \& Schuster, New York (2000)

49. Quan-Haase, A., Young, A.L.: Uses and gratifications of social media: a comparison of Facebook and instant messaging. Bull. Sci. Technol. Soc. 30(5), 350-361 (2010)

50. Quan-Haase, A., Young, A.L.: The uses and gratifications (U\&G) approach as a lens for studying social media practice. In: Fortner, R.S., Fackler, P.M. (eds.) The Handbook of Media and Mass Communication Theory, pp. 269-286. Wiley, Hoboken (2014)

51. Quan-Haase, A., Martin, K., McCay-Peet, L.: Online conversation and information management on Twitter: preliminary findings of interviews with digital humanities scholars. Paper presented at the Social Media \& Society International Conference, Toronto (2014) 
52. Reinhard, C., Dervin, B.: Media uses and gratifications. In: Eadie, W. (ed.) 21st Century Communication: A Reference Handbook, pp. 506-516. Sage, Thousand Oaks (2009). doi:http://dx. doi.org/10.4135/9781412964005.n56

53. Ross, C., Terras, M., Warwick, C., Welsh, A.: Enabled backchannel: conference Twitter use by digital humanists. J. Doc. 67(2), 214-237 (2011)

54. Sethi, L.: Social media addiction: 39,757 years of our time is collectively spend on Facebook in a day! Dazeinfo. http://dazeinfo.com/ (2015). Cited 14 Jan 2015

55. Sin, S.-C.J., Kim, K.-S.: International students' everyday life information seeking: the informational value of social networking sites. Libr. Inf. Sci. Res. 35(2), 107-116 (2013)

56. Smock, A.D., Ellison, N.B., Lampe, C., Wohn, D.Y.: Facebook as a toolkit: a uses and gratification approach to unbundling feature use. Comput. Hum. Behav. 27(6), 2322-2329 (2011)

57. Social media. (n.d.). Merriam-Webster online. http://www.merriam-webster.com/dictionary/ socialmedia. Cited 14 Jan 2015

58. Sundén, J.: Material Virtualities: Approaching Online Textual Embodiment. Peter Lang, New York (2003)

59. Terras, M.: Adventures in Digital humanities and digital culture heritage. Plus some musings on academia. Melissa Terras' Blog. http://melissaterras.blogspot.ca/2012/04/is-blogging-andtweeting-about-research.html (2012). Cited 14 Jan 2015

60. Throop, B.B.: Cyberbullying has 'hugely disproportionate impact on women and girls'. CBC News. http://www.cbc.ca/ (2014). Cited 14 Jan 2015

61. Twitter: Best Practice: Tweet in the moment. http://media.twitter.com/best-practice/tweet-inthe-moment (2014). Cited 14 Jan 2015

62. Van Eperen, L., Marincola, F.M.: How scientists use social media to communicate their research. J. Transl. Med. 9(1), 199 (2011)

63. Verma, I.M.: Editorial expression of concern and correction. Proc. Natl. Acad. Sci. USA 111(29), 10779 (2014). doi:10.1073/pnas.1412469111

64. Whiting, A., Williams, D.: Why people use social media: a uses and gratifications approach. Qual Mark Res. 16(4), 362-369 (2013)

65. Yadamsuren, B., Heinstrm, J.: Emotional reactions to incidental exposure to online news. Inf. Res. 16(3), paper 486 (2011)

66. Young, A.L., Quan-Haase, A.: Privacy Protection Strategies on Facebook. Inf. Commun. Soc. 16(4), 479-500 (2013)

67. Yuan, Y.C., Zhao, X., Liao, Q., Chi, C.: The use of different information and communication technologies to support knowledge sharing in organizations: from e-mail to micro-blogging. J. Am. Soc. Inf. Sci. Tecnol. 64(8), 1659-1670 (2013)

68. Zhang, L., Pentina, I.: Motivations and usage patterns of Weibo. Cyberpsychol. Behav. Soc. Netw. 15(6), 312-7 (2012) 